[REVIEW]

\title{
Contrast in Phonology: Theory, Perception, Acquisition
}

Ed. by Peter Avery, B. Elan Dresher and Keren Rice, Phonology and Phonetics 13, Mouton de Gruyter, Berlin/New York, 2008, vi+351pp.

\author{
KOHEI NISHIMURA \\ Aichi Shukutoku University*
}

Keywords: phonology, phonological contrast, phonological theory, perception, acquisition

\section{Introduction}

Phonological contrast has played a central role in modern linguistic inquiry from its beginning, when Ferdinand de Saussure argued in his posthumous work (1916) that what is important in distinguishing one word from another is not the sounds themselves, but the contrasts of those sounds. His view, which places greater emphasis on contrast than on actual phonetic properties, intelligibly represents the abstractness of the human language ability, and has been one of the key concepts not only in linguistics but also in other areas of cognitive science. His ideas also outline the traditional difference between phonology and phonetics; while phonetics analyzes speech sounds as physical entities, phonology typically focuses on properties which reflect differences in meaning and behaviors related to such differences among physical sound properties. In this sense, the study of contrast is symbolic of phonological inquiry.

Following Saussure, a large number of investigations on phonological contrast, including Trubetzkoy (1939), Jakobson and Halle (1956), Chomsky and Halle (1968), and Archangeli (1988), have shed new light not only on phonological inquiry but also on the development of linguistics as a whole. In these studies, important mechanisms such as phonemes, distinctive features, feature hierarchies and geometry, and the underspecification of features have been proposed and developed to account for phonological contrast and its ramifications.

* I would like to thank two anonymous reviewers for their valuable comments and suggestions. 
Contrast in Phonology: Theory, Perception, Acquisition is a collection of contemporary studies which discuss phonological contrast in human language. The articles in this book are based on talks presented at the Second International Conference on Contrast in Phonology held at the University of Toronto in 2002. As the title indicates, they deal with issues in phonological contrast in three areas, theory, perception, and acquisition, which constitute the core of phonological inquiry today.

The book begins with an introduction by the editors, which briefly outlines the significance of each of the thirteen studies comprising the content. Readers can thus first grasp the main points of each of the studies to get an understanding of the specific issues they cover. Following the introduction, the main text is divided into the three sections named in the title: phonological theory, perception, and acquisition. The acquisition section is further divided into two sub-sections: first language (L1) acquisition and second language (L2) acquisition.

\section{Theory}

The first section of the book consists of five articles concerned with theoretical issues in phonological contrast. As mentioned above, studies on phonological contrast have vigorously advanced not only the development of phonological theory, but also that of other linguistic areas; the articles in this section also provide several profound suggestions for theoretical models of phonology.

The section begins with three articles that discuss hierarchies in which phonological features are assumed to be organized within hierarchical relationships based on the articulation of linguistic sounds (Jakobson and Halle (1956) and others). The first study of this section is "The contrastive hierarchy in phonology," written by B. Elan Dresher. The author considers methods for assigning contrastive features in phonological theory through a comparison of two fundamentally different approaches: one which depends on the existence of minimal pairs, and the other on a feature hierarchy. $\mathrm{He}$ briefly reviews the first approach, and then goes on to claim that even though such an approach is intuitively plausible, it is inadequate for assigning an appropriate set of contrastive features, pointing out that such an approach may lead to problematic conclusions in some situations. As an alternative to this "minimal pair" approach, the author illustrates a method that determines a set of contrastive features based on a hierarchy of phonological features and the Successive Division Algorithm, which generates 
plausible sets of distinctive features for languages.

In his article "Prophylactic features and implicit contrast," Daniel Currie Hall analyzes Czech voicing assimilation by adopting the feature hierarchy approach and the Successive Division Algorithm argued for in the previous article by Dresher. He points out that Czech voicing assimilation cannot be explained correctly under the strong version of the contrastivist hypothesis, which stipulates that redundant features are not present in phonological computation. To solve this problem, he proposes a weaker version of the contrastivist hypothesis that permits inactive redundant features to be preset in the phonological system, including underlying representations. Under this view, he provides an explanation of Czech voicing assimilation while introducing "prophylactic features," which, he argues, are present in the underlying representations of some Czech words but completely inert in any phonological operations.

In the third article, "Contrasts in Japanese: A contribution to feature geometry," S.-Y. Kuroda also argues in favor of phonological contrast based on feature geometry. He illustrates the roles of voicing features in three patterns of voicing assimilation in Japanese, namely regressive assimilation, progressive assimilation, and rendaku (sequential voicing). He points out that in these assimilation patterns voicing segments do not behave in a consistent way: regressive assimilation is triggered by any voiced consonant, while progressive assimilation is caused only by voiced obstruents and nasals, but not liquids or glides, and only voiced obstruents are crucial in rendaku. To account for this inconsistency, Kuroda proposes a feature geometry and associated parameters based on the aerodynamics of the articulatory organs. Under this geometry, voicing features are only contrastive in obstruents and nasals, and not liquids or glides. By separating rendaku from the voicing assimilation mechanism for which he argues, such voicing feature behaviors correctly address Japanese voicing assimilation.

The proposals made by Hall and Kuroda plausibly account for voicing assimilation in their respective studies of Czech and Japanese. However, it remains debatable whether the mechanisms proposed in their studies are appropriate in other phonological systems, because such theoretical modifications may result in the generation of ungrammatical surface structures and operations. Therefore, their proposed theories must be tested in future research to see if they correctly describe and predict phonological behaviors not only in the languages they have observed but also in other languages without overgeneration.

In their study "Quasi-phonemic contrast and the fuzzy inventory: Exam- 
ples from Scottish English," James M. Scobbie and Jane Stuart-Smith raise a query for the traditional view of phonology in which phonological contrast is highly abstract and categorical. Through an analysis of the consonant and vowel inventories in Scottish Standard English, the authors claim that some phonological contrasts in a language should be treated as a gradient phenomenon rather than being clear-cut at the phonological level. According to the Scottish English data they present, the phonological inventory of this language contains marginal contrasts, which the authors call "quasi-phonemic" contrasts. To capture such quasi-phonemic phenomena, the authors argue that phonologists should accept more adaptable frameworks, such as exemplar approaches, that allow phonology to reflect a range of data based on phonetic variation, sociolinguistics, and other areas (Pierrehumbert (2001) and others). Under such approaches, they argue, greater flexibility is provided to phonological analysis.

The last article of this section is "Effects of contrast recoverability on the typology of harmony systems," written by Gunnar Ólafur Hansson. Hansson dissects patterns of neutralization in phonological harmony in several languages and presents a typology of phonological harmony systems. An interesting asymmetry between consonant neutralization and vowel neutralization is reported: while the neutralization of lexical contrasts is often found in typologies of consonant harmony systems, such patterns are quite rare in typologies of vowel harmony systems. The author claims that the "recoverability" of lexical contrasts plays a crucial role in systems of harmony which causes asymmetry between vowels and consonants in phonological harmony. He cites three factors contributing to differences between the behaviors of vowels and those of consonants: (i) differences in the nature of vowel space and "consonant space," (ii) differences in trigger/target similarity, and (iii) the fact that in the case of vowels, a neutral vowel tends to be the "odd man out." Considering these facts, Hansson concludes that lexical contrasts in vowel harmony systems are far less easily recoverable and hence harder for successive generations of learners to discover and internalize than are corresponding contrasts in consonant harmony systems. He also notes that it is impossible for output-oriented constraintbased frameworks like standard Optimality Theory (hereafter OT; Prince and Smolensky (1993)) to handle the harmony patterns he describes in his study.

As outlined above, the five studies in this section provide profound suggestions for several theoretical models of phonology. However, I am dissatisfied with the fact that this section contains few arguments relating to the framework of OT, which has been the dominant trend in theoretical 
phonology since the mid-1990s. Different from rule-based theories, an explanation of phonological contrast within OT does not require any specific mechanisms because any systematic patterns in the surface level are simply outcomes of constraint interaction. In other words, phonological contrast in a language is not what is salient before phonological operations apply, but rather simply a result of constraint interaction no different from other phonological phenomena. As we have seen, of the five studies in this section, only Hansson mentions the OT framework, while several of the studies in the following two sections of this book contain attractive arguments and suggestions that address this framework, as we will see later. This section would be more convincing, therefore, if it too included more arguments on phonological contrast within the OT framework.

\section{Perception}

The second section of this book discusses the perception of phonological contrast. Today, the study of perception is a very active area of research, with animated discussions in the field of linguistics (e.g. Ishihara (2003), Hirotani (2005), Pisoni and Remez (2005)), and in phonology in particular (Hume and Johnson (2001), Flemming (2004), Steriade (2009) and others). In all three studies of this section, the authors discuss experiments designed to examine the role of phonological contrast in a number of languages.

The section begins with the article "The impact of allophony versus contrast on speech perception," written by Amanda Boomershine, Kathleen Currie Hall, Elizabeth Hume, and Keith Johnson. They examine the perception of three coronal consonants, namely [d], [r], and [ð], and conduct experiments with Spanish-speaking and English-speaking listeners. These sounds behave differently in each of the two languages: in English, [d] and [r] are found to be allophones of a single phoneme, and are distinctive from [ð], while in Spanish, [d] and [ð] are allophonic variations and phonemically contrastive with $[r]$. The results of their experiments show that phonemic contrast strongly influences speech perception and that surface phonetic detail influences perceptual discrimination judgments. The authors then compare two types of phonological models: a phonological inferencing model and a lexical processing model (e.g. the exemplar model; Pierrehumbert (2001)). They put a higher value on the latter because such models can deal with the differences in perception one finds within languages between pairs of the "same" allophone of one phoneme (e.g. [d]/[d]) and "different" 
allophones of one phoneme (e.g. [d]/[ð]).

Jeff Mielke, in his article "Interplay between perceptual salience and contrast: /h/ perceptibility in Turkish, Arabic, English, and French," discusses the relationship between perceptual salience and contrast by examining the phonological contrast between $/ \mathrm{h} /$ and its absence for the speakers of four languages. The results of his experiments reveal that $/ \mathrm{h} /$ deletes in environments where this sound is difficult to perceive crosslinguistically, although there are also language-specific differences. In conclusion, he demonstrates how acoustic cues, functional load, and perceptual distance interact in the perception of phonological contrast.

In his article "Self-organization through misperception: Secondary articulation and vowel contrasts in language inventories," Alexei Kochetov discusses the physical limitations of articulation and the perception of speech sounds, focusing on two types of phonological contrast: high vowel contrasts, that is, $/ \mathrm{i} /$ versus $/ \mathrm{y} /$ and $/ \mathrm{u} / \mathrm{versus} / \mathrm{u} /$, and secondary articulation contrasts in consonants, that is, plain segments $(C)$ versus palatalized $\left(\mathrm{C}^{\mathrm{j}}\right)$, velarized $\left(\mathrm{C}^{\gamma}\right)$, or labialized $\left(\mathrm{C}^{\mathrm{w}}\right)$ segments. He reports a strong crosslinguistic tendency for these contrasts: a language tends to avoid having both distinctive secondary articulation contrasts and multiple distinctions in rounding/backness in its inventory. The author argues that this general tendency of human language is caused by limitations of speech production and perception, supporting this claim by conducting simulations of the undershooting of a phonological inventory. In his view, an inventory with complex contrasts tends to be ruled out, and a relatively simple inventory will be naturally selected without any specific a priori knowledge of markedness, such as restrictions on the lexicon or OT constraints.

\section{Acquisition}

The third and final focus of this book is the role of phonological contrast in language acquisition. It goes without saying that in both first and second language acquisition, the knowledge of phonological contrast in the target language is essential and indispensable. The study of language acquisition has provided much quality data and informed other areas of linguistics. In particular, by being linked with the study of perception, its importance has grown substantially in recent years as shown in the following studies here. This section on acquisition is further divided into two subsections: the former discusses first language (L1) acquisition and the latter second language (L2) acquisition. 
4.1. First Language (L1) Acquisition

This sub-section introduces two studies of infant language acquisition. In the first article, "The role of contrast in the acquisition of phonetic systems," Daniel J. Weiss and Jessica Maye discuss an interesting relationship between the acquisitional process and the discrimination of contrast. There are some phonetic contrasts that are difficult to discriminate for infants, while adults, whose native language phonemically utilizes these contrasts, easily perceive them. The authors hypothesize that the statistical distribution of speech sounds in an infant's input may be a driving factor in the process of facilitation of such contrasts. To test this hypothesis, they design an experiment on the discrimination of voicing contrasts on velar stops with infants from English-speaking families; they compare the discrimination of infants familiarized to a bimodal distribution of the sounds with that of infants given no relevant pre-exposure. The results of their experiment support their hypothesis: infants exposed to a bimodal distribution demonstrate better discrimination of contrasts.

The other article in this sub-section is, "How does Place fall into place? The lexicon and emergent constraints in children's developing phonological grammar," written by Paula Fikkert and Clara Levelt. They focus on the development of place of articulation features through an examination of consonant harmony in a database of Dutch children's speech. Their close observations reveal a fixed order to the acquisition of place features, and show that consonant harmony in infants' speech is an epiphenomenon of this general developmental pattern. They argue that this pattern of acquisition can be explained by assuming that in the initial stage, underlying representations are not segmentalized and that they gradually become more specified along with the development of the lexicon. The authors conclude that the phonological system in the initial stage is completely different from the system in later stages.

\subsection{Second Language (L2) Acquisition}

The final part of this book contains three studies on second language acquisition by adult speakers. In their study "Learning to perceive a smaller L2 vowel inventory: An Optimality Theory account," Paul Boersma and Paola Escudero discuss the formalization of L2 acquisition within the framework of OT, and analyze the acquisition of Spanish vowels by Dutch speakers. They report the results of their listening experiments as follows. While in the initial stage of learning, Dutch learners tend to identify Spanish vowel tokens with the Dutch vowels most similar to them, simply 
depending on auditory similarity. Later, they modify their perceptions according to the Spanish vowel contrast system. The authors then present an Optimality-Theoretic account to illustrate how learners converge on the appropriate perception grammar based on the system of the target language. It should be noted that this study convincingly demonstrates that Optimality-Theoretic accounts can be utilized in studies of perception and acquisition, while also sharing some insights with other computational models such as the connectionist model.

In "The effect of perceptual factors in the acquisition of an L2 vowel contrast," Juli Cebrian examines the lax-tense contrast in English high and mid front vowels by speakers of the Eastern variety of Catalan, which distinguishes vowels spectrally but not temporally. The author conducts several experiments on the perception and production of these vowels to show the role of native and non-native cues in the categorization of second language contrast. The results reveal that Catalan learners utilize duration cues in their perception and production of the English high vowels even though such information is not distinctive in vowels of their mother tongue. The author then concludes that vowels are not acquired individually depending on phonetic cues, but rather as part of a contrast system, with the consequence that the formation of one vowel category can affect the categorization of other vowels in the inventory.

In the final article of this book, "Some reflections on abstractness and the shape of inputs: The case of aspiration in English," Heather Goad discusses the abstractness of lexical representations. She examines the acquisition of the three-way contrast in Thai (voiced, voiceless unaspirated, and voiceless aspirated) by native speakers of English, where aspiration is found in some contexts but is not distinctive, and compares this with the acquisition by native speakers of French, where aspiration is not found. The results reveal no significant difference between English and French speakers in the perception of Thai aspirated/unaspirated contrasts. This result can be accounted for if English indeed lacks this contrast in its underlying representations, even though aspirated segments are found in English. In conclusion, the author emphasizes the abstractness of input representation in phonology, and the difference between phonology and phonetics; the former does not necessarily always align with the latter.

\section{Summary}

As briefly reviewed above, this collection covers issues in various as- 
pects of phonological contrast. It is convincingly demonstrated that the three main areas of the book, theory, perception, and acquisition, are firmly related to each other in phonological studies. Another insight presented is that despite its long history, the study of phonological contrast still involves a number of issues that offer profound suggestions for phonological inquiry. Readers will be convinced that just as in the past, contrast will continue to occupy a central role in phonology while also impacting other linguistic fields.

\section{REFERENCES}

Archangeli, Diana (1988) “Aspects of Underspecification Theory," Phonology 5, 183-207.

Chomsky, Noam and Morris Halle (1968) The Sound Pattern of English, Harper and Row, New York.

Flemming, Edward (2004) "Contrast and Perceptual Distinctiveness," The Phonetic Base of Markedness, ed. by Bruce Hayes, Robert Kirchner and Donca Steriade, 232-276, Cambridge University Press, Cambridge.

Hirotani, Masako (2005) Prosody and LF Interpretation Processing Japanese Whquestions, Doctoral dissertation, University of Massachusetts, Amherst.

Hume, Elizabeth and Keith Johnson (2001) "A Model of the Interplay of Speech Perception and Phonology," The Role of Speech Perception in Phonology, ed. by Elizabeth Hume and Keith Johnson, 3-26, Academic Press, New York.

Ishihara, Shinichiro (2003) Intonation and Interface Conditions, Doctoral dissertation, MIT.

Jakobson, Roman and Morris Halle (1956) Fundamentals of Language, Mouton, The Hague.

Pierrehumbert, Janet B. (2001) "Exemplar Dynamics: Word Frequency, Lenition and Contrast," Frequency and the Emergence of Linguistic Structure, ed. by Joan Bybee and Paul Hopper, 137-157, John Benjamins, Amsterdam.

Pisoni, David B. and Robert E. Remez, eds. (2005) The Handbook of Speech Perception, Blackwell, Oxford.

Prince, Alan, and Paul Smolensky (1993) "Optimality Theory: Constraint Interaction in Generative Grammar," technical report, Rutgers University Center for Cognitive Science. [Published by Blackwell, Oxford, 2004.]

Saussure, Ferdinand de (1916) Course in General Linguistics, ed. by Charles Bally and Albert Sechehaye, with the collaboration of Albert Riedlinger, translated by Wade Baskin, 1959, McGraw-Hill, New York.

Steriade, Donca (2009) "The Phonology of Perceptibility Effects: The P-map and Its Consequences for Constraint Organization," The Nature of the Word: Essays in Honor of Paul Kiparsky, ed. by Kristin Hanson and Sharon Inkelas, 151-180, 
MIT Press, Cambridge, MA.

Trubetzkoy, Nikolai S. (1939) Principles of Phonology, translated by Christiane Baltaxe, 1969, University of California Press, Berkeley.

[received December 20 2009, revised and accepted April 25 2010]

Division of Foreign Language Education

Aichi Shukutoku University

23 Sakuragaoka, Chikusa, Nagoya

Aichi 464-8671

e-mail: knishimu@asu.aasa.ac.jp 